BIORHEOLOGY, $27 ; 3-19,1990$

$0006-355 X / 90 \$ 3.00+.00$ Printed in the USA.

Copyright (c) 1990 Pergamon Press plc. All rights reserved.

FLUID MECHANICS AND BIORHEOLOGY*

Alfred L. Copley

Laboratory of Biorheology, Polytechnic University,

Brooklyn, New York 11201, USA

\begin{abstract}
The term 'rheology', which denotes the study of deformation and flow of matter in general, logically also includes fluid mechanics. However, as $I$ was told by my friend, the late George $w$. Scott Blair, it was decided in 1929 in Washington, D.C. at the Foundation Meeting of the Society of Rheology, in which he participated, to limit rheology to non-Newtonian systems. The reason for this decision was to protect the new science of rheology from being swamped. However, no limitation to non-Newtonian fluids was imposed in several early conferences, which led to the organization of the science of biorheology. These conferences played and continue to play an important role in the development of biorheology. Since many biological systems and blood in particular are multicomponent disper-
\end{abstract}

Key Words: Biofluid mechanics, biomechanics, biorheology, endoendothelial fibrin(ogenin) lining, fluid mechanics, hemodynamics, hemorheology, history of medicine, history of science, hydrodynamics, Leonardo da Vinci, perihemorheology, rheology, vessel-blood organ.

* Opening Address, 2. International Symposium on Biofluid Mechanics and Biorheology, Munich, F.R. Germany, 25-28 June 1989, Satellite Symposium of the VII. International Congress of Biorheology, Nancy, France, 18-23 June 1989. 
sions, their overall properties are non-Newtonian even if the individual components are Newtonian. Hence, classical fluid mechanics analyses have been presented at conferences of biorheology, including hemorheology, thus far its most active field.

The term 'biofluidmechanics' was introduced by Bugliarello, who defined it as 'the use of fluid mechanics for the study of biological flows in the various life sciences, both basic and applied' (1). Recently George Bugliarello and I discussed fluid mechanics in the context of fluids of biological origin. His thoughts may be summarized as follows: Fluid mechanics is really 'a combination of mechanics and rheology, in the sense that the principles of mechanics are applied in a context defined by the rheological properties of the fluid. In classical hydrodynamics the fluid is considered inviscid' (2). In traditional fluid mechanics, the 'stress/rate of strain' relationship of the fluid is linear, that is 'Newtonian', a stress-independent viscosity; in biological fluid mechanics the stress/rate of strain relationship of the fluid (e.g., blood) is generally non-linear ('non-Newtonian'), and system properties are 'stress-dependent and even time-dependent' (2).

As I participated in the organization and development of biorheology as a life science, I shall give to some extent a brief personal account and emphasize mainly the present status of biorheology. It is not generally realized or widely known that, in particular during the past decade, the scope of the science of biorheology has been widened and changed fundamentally. I shall emphasize the present new and widened scope of biorheology. Furthermore, I shall acquaint you with my thoughts regarding biofluid mechanics in relation to biorheology.

The first time I heard the term 'rheology' was in 1936, when I was a student of physical chemistry at the University of Basel in Switzerland. In 1937 I left for the 
United states and in 1939 I started in Kansas City my first experimental studies on flow properties of blood at the Hixon Laboratory for Medical Research at the University of Kansas School of Medicine. The studies resulted in a paper, published in 1942 in the Journal of General Physiology, a publication of the Rockefeller Institute in New York City (3). I mention this, because it was this communication which was particularly greeted by the rheologists, both in the United States and in Western Europe, and ultimately led to the organization of biorheology as a science.

In 1944 there was in Oxford a Conference on Rheology and Medicine (4) to which I was invited to act as its chairman. The meeting was organized by the British Rheological club, later renamed the British society of Rheology. Because of the war, I could not participate in it. After the war, I was invited by the scientific Committee of the I. International congress on Rheology, held in Scheveningen, Holland in 1948, to give a Plenary Lecture, entitled 'Rheological problems in Biology' (5). From its introduction I should like to cite the following: 'It is necessary to recognize the significance of rheological problems in the future of biological sciences. These problems may develop eventually in a science branch of its own, for which I should like to propose for the sake of convenience the term 'bio-rheology'. It may be predicted that bio-rheological inquiries into the nature and origin of life will grow in scope and volume'. From the concluding remarks of this Plenary Lecture I cite the following: 'I am convinced that rheology will play a very important role in the biological sciences including medicine of tomorrow. As observations of the flow of blood helped initiate the science of rheology, it is my belief that from continued observations of this very special part of life, namely blood and of blood constituents, a combination of the sciences of rheology and biology is bound to serve the well-being of our species'.

Three years later, the 25. Anniversary Meeting of the American Institute of Physics, of which the society of 
Rheology is one of its Founding societies, was held in Chicago. I was invited by the society of Rheology to give a General Lecture, entitled 'The Rheology of Blood' (6). In this lecture I introduced the term 'hemorheology', which I defined as follows: 'Hemorheology is concerned with the deformation and flow properties of cellular and plasmatic components of blood in macroscopic, microscopic and submicroscopic dimensions, and with the rheological properties of the vessel structure with which blood comes into direct contact'. This definition was adopted at the Foundation Meeting of the International Society of Hemorheology, held at the University of Iceland in 1966. Three years later during the 2. International conference on Hemorheology (7), held at the University of Heidelberg, the scope of the Society was enlarged to include all fields of biorheology and accordingly its name was changed to The International society of Biorheology (8).

In the definition of hemorheology, which I gave in 1951 (6), I already implied that the blood and the vessel wall are an entity, which I proposed in 1960 in a Plenary Lecture on the Endoendothelial Fibrin Lining before the VIII. International Congress of Hematology in Tokyo (9). In 1981, at the IV. International Congress of Biorheology, held in Tokyo, I defined this entity of the vessel wall and the blood as an organ, named the 'vessel-blood organ' (10). This concept favors a new definition of hemorheology as the biorheology of the vessel-blood organ, its constituents and of the processes involved in both its two portions as well as in their interrelations. The vessel-blood organ penetrates all other organs, similar to the nervous system (10). I consider the endoendothelial fibrin(ogenin) lining (EEFL) as the crucial boundary or interface between the two portions of the vessel-blood organ, viz., the vessel wall and the blood. Contrary to the general belief, I postulated the EEFL as the main filtration barrier for transcapillary transport (11).

Two fields of biorheology, viz. hemorheology and hemo- 
dynamics, have a long history in biomedical science (8). In the third century B.C., Herophilus (before 300 B.C.) and Erasistratos (310-250 B.C.) from the famous medical school of Alexandria, Egypt are probably the first to study hemodynamics and Erasistratos likened the heart to a pump (8). Leonardo da Vinci (1452-1519), who embodied a kind of unity or affinity between art and science, fluctuated in his views on the circulation of the blood (8). At times he accepted the view of Aristotle (384-322 B.C.) that the flow of blood has its origin in the heart. At other times he accepted the concept of Galen (129-199) on the motion of the blood, carrying the natural spirits on the venous side and the vital spirits on the arterial (8).

Leonardo da Vinci failed to understand the circulation of the blood $(8,12-16)$. Nevertheless he made several important contributions concerning hemodynamics, hemorheology and other fields of biorheology. As they are not sufficiently known or have not yet been known, I should like to mention briefly some of them. In his comments on the mechanism of the heart and other organs Leonardo emphasized 'the four powers of nature', which he identified as movement, weight, force and percussion. He considered the heat of the heart, created by the friction of fluid particles, as the motive force of the blood in the vessels (14). Leonardo discovered two more chambers of the heart. He suggested that the necessary friction could be produced by tossing blood from the upper chambers to the lower ventricles and back. He did not merely describe the size and shape of the auricles (atria), but he considered both atrial chambers to contract together while the ventricles were in diastole (14).

Leonardo had an abiding interest in studies of hydrodynamics or what he called 'the nature of water' (14). He can be credited to be the first in using models in the study of hemodynamics. In examining the operation of the heart, Leonardo $(12,16)$ referred to his experiments on the flow of water. He discovered in building canals, that ed- 
dies formed in the flow of water from a narrow to a wider channel. Leonardo applied this knowledge to the flow of blood through the valves of the heart. He was aware of similarities between the anatomy of human subjects to that of other mammalian species. Leonardo, therefore, used for his studies the aortic and pulmonary valves of a bull's heart to show their 'true shape'(14-16). He described in some detail a technique for the construction of models of thin glass, beginning with the pouring of wax into these heart valves (14-16). Leonardo made drawings of eddies of blood which passed through the aortic valve, closing the cusps from side to side (16).

Leonardo da Vinci can also be credited to be the first to recognize the elasticity of the vessel walls in his description of their filling and emptying during systole and diastole (14). Several years ago I also found from reading the English translation of texts by Leonardo $(8,12)$, which accompany his drawings, that he was the first to predict the existence of capillary blood vessels, 'vene chapillari'. This recognition was likewise not mentioned in the biomedical literature including that of the circulation. Leonardo used the word 'vene' to mean either vein or vessel (13). Futhermore, I found that Leonardo da Vinci was keenly aware of the destruction and regeneration of blood. He stated that blood 'continually dies and is renewed' $(8,12)$. The historian of medicine Charles singer made the appraisal that 'the anatomy of Leonardo was scientifically the equal of anything that appeared until well into the seventeenth century' (17).

In this communication I have dwelt in considerable length on some of the attainments of Leonardo da Vinci in the history of the life sciences including biorheology. As a scientist Leonardo, who had no academic background but was not ignorant of academic science, was self-taught and a keen, exacting observer. In the pursuit of art and science 
he was endowed with what I like to call 'the creative spark' (18), which is the initiator of diverse creative processes. 'The creative spark' is the prime mover in the advancement of knowledge in science and in expanding felt life experience in works of art. Furthermore, 'the creative spark' provides what is essential in the unity of art and science, which Leonardo da Vinci personifies as a master.

In the literal translation of the term, hemodynamics deals with the dynamics of blood flow. Such a translation does not take into account the shapes and inner lining of the great variety of blood vessels, in which the flowing blood is contained, nor the changes in blood pressure affecting the flow of blood. Hemodynamics can also not be limited to the macrocirculation, as hemodynamics affects also the microcirculation. Oka stated 'how hemodynamics differs from hemorheology can best be explained by comparing fluid mechanics and rheology' (19). Fluid mechanics in life processes involves not merely the vessel-blood organ, but, for instance, the fluids in the perivascular spaces, viz., the interstitial fluids and the lymph. The field of perihemorheology (20), a newly proposed term, indicates the biorheology of perivascular fluids and structures. Biological fluids in context with life processes include, among others, the cerebrospinal fluid, the flow in vivo of bile, urine, the fluids produced by various glands and excreted through channels or ducts. Hemodynamics, also directly related to hemorheology, belongs, therefore, to the large field of the mechanics of fluids participating in life processes.

At the symposium of Biorheology, held as part of the 4. International Congress on Rheology at Brown University, Providence, Rhode Island (USA) in 1963, my opening Address was entitled: 'On the Validity of Classical Fluid Mechanics in Biorheology' (21). I pointed out some of the phenomena, in which an apparent deviation from the principles of classical fluid mechanics exists in the rheology of blood. Firstly, I mentioned the so-called plasmatic zone, a layer 
free of red and white blood cells in the in vivo circulation and, secondly, our observations that 'the apparent viscosity in capillary viscometers can be affected by coating the glass surface with different substances'. The action of different coatings on apparent viscosity can be highly significant. A rate of flow through a capillary tube is dependent on the character of the coating, which has been demonstrated with water in 1928 by Traube and Wang (22) and for blood systems by me in 1958 (23) and subsequently by Copley and Scott Blair (24-28). The decreased apparent viscosity in glass capillaries coated with fibrin was referred to by oka (29) as the 'Copley-Scott Blair phenomenon' $(11,29,30)$.

The existence of slip along the wall of a magnitude depending on the characteristics of the coating (21) would 'require the replacement of the poiseuille equation by an extended equation due to Helmholtz' (21), published in 1868 (31). The assumption of slip in a molecularly homogeneous Newtonian fluid has been rejected in classical fluid mechanics (21), but is quite feasible in the case of a dispersion such as blood. Copley and Scott Blair established the existence of 'wall adherence' on the basis of an index of blood systems bordering on surfaces and traveling in a capillary tube (23-28). In my opening Address in 1963, I thought that 'the relation to classical fluid mechanics could be reestablished, if it could be considered in flow with wall adherence that the principle of conservation of mass was no longer valid, since the adhering portions of the fluid would remain immobile; the necessary corrections to the basic equations arising from this fact would then have to be introduced' (21).

I also pointed out that 'if wall adherence can be demonstrated in a closed system, it may then be also compatible with Poiseuille's concept of an immobile layer' (21), for which copley and staple found some experimental evidence in 1959 in the living microcirculation of the hamster's cheek pouch (32). Slip on the immobile layer as an assump- 
tion would still be compatible with the assumption of zero velocity at the wall. I concluded that 'a close relation of classical fluid mechanics and rheology rather than a contradiction between them' could thus exist (21). Moreover, I emphasized the possibility 'that entirely new approaches in physics other than classical fluid mechanics could be applied to our problems in biorheology'. We should be aware of the possibility that in the living system as well as in extra-corporeal flow of biological materials, 'mechanochemical interactions may occur which will invalidate the purely mechanical approach as exemplified in fluid mechanics' (21).

Twenty-six years have elapsed since I proposed the earlier mentioned considerations (21). I believe that anyone interested in fluid mechanics in context with life processes will benefit from reading the contribution by Aharon Katchalsky and A. Oplatka, entitled 'Mechanochemistry'. It appeared in the Proceedings of the same Congress on Rheology, published in 1965 (33).

Meanwhile, the science of biorheology has advanced, as it can no longer be limited to the rheology of fluids of biological origin. We can no longer ignore the fact that we have to differentiate between fluids of biological origin which are in context with life processes from biological fluids which are not in such a context, e.g., oils, latex, silk, milk products, among others.

I should like to reemphasize what I have stated in 1981 at the IV. International congress of Biorheology. In a Plenary Lecture 'The Future of the Science of Biorheology' (10) I proposed biorheology as the missing link in the life sciences. It was then stressed: 'We all as practicing biorheologists, regardless of whether our activities and contributions concern theoretical, experimental or applied (including clinical) pursuits, will have to exercise the mission of disseminating biorheology as the important link, missing thus far in most life sciences toward their ad- 
vancement' (10). The reason or explanation for the missing link was recently given by Alex Silberberg (34) as follows: 'The most characteristic aspect of life processes may well be the fact that they involve changes in the shape of the organism and a variety of relative movements both within the living system and of the living system relative to its living or inanimate environment. All structural, organisational features of the system and the chemical processes which run in it are to a large part designed with this ultimate objective. Life is that which imbues a system with the ability to deform and flow in consequence of self-generated forces. The ability to do so is an essential requirement in system replication, in procreation and in the ingestion of the necessary energy-rich, chemical materials which maintain the life functions and allow waste to be eliminated. It follows therefore that the manner in which biological systems deform and flow, how they cope with their mechanical environment and the mechanical aspects of their nature, namely how they perform biorheologically, is to be seen as a basic, if not the only, evolutionary 'design consideration' (34)'.

Silberberg (34) contributed the following remarks on the relationship between biomechanics and biorheology: 'It should be more generally perceived that biomechanics and biorheology are but the two sides of the same coin, the one dealing with the dynamics and kinetics of biological systems, i.e., the forces acting on the system, the other with their response characteristics, i.e., the forces internally generated in response by the rheological nature of the system. In many instances of course both 'external' and 'internal' forces are the biorheological consequence of structure and mechanical organization of parts of a living system. This leads to what I call 'matching', another evolutionary 'design consideration'(34)'.

In an Editorial of BIORHEOLOGY in 1986 (35) Alex Silberberg and I stated: 'Indeed, the science of biorheology 
is more than just a branch of rheology. Technically, of course, it deals with biological materials in deformation and flow, i.e., their rheology, both extra vivum and in the biological context. Unlike straight rheology, however, biorheology is concerned not only with the 'how' but also and predominantly with the 'why' biological materials behave as they do'. I believe this new scope of the science of biorheology is of importance to anyone appreciating its significance. I, therefore, continue to quote from this Editorial: 'The rheological properties of biological materials and their cellular and molecular level interpretations are thus not studied purely as material attributes. They are inextricably linked to the transport and motility requirements and thus to the molecular, structural and thermodynamic description of the biological system. The existence of mechanical stresses, other than a hydrostatic pressure at an appropriate level, is responsible not only for the establishment of pressure gradients, but also for the creation of the requisite chemical potential, including electrochemical potential gradients which feed and clear the living system. Mechanical energy losses, of the frictional type, which occur in biological materials, are predominantly the results of the relative flow of components and the viscous dissipation which this entails. Much of biorheological investigation is, therefore, concerned with the interpretation of observations in terms of structural, molecular morphology and a relative component flow'(35)'.

'There are fundamental tasks facing biorheology asking it to provide the understanding for why Nature built in the way it did, particularly why certain structures and organisations, using certain materials and dimensions, have evolved. Since movement and the accompanying transfer of energy is the essence of life processes, problems of deformation including flow lie particularly close to the center of things insofar as living matter is concerned. Clearly, biorheology is not meant to be all encompassing, but much more feeds into its study than the rheological characteriza- 
tion of a biologically derived material. The essence of a living system requires it to be out of equilibrium with respect to at least some of its components. Chemical regeneration, growth and decay are thus inevitably phenomena accompanying purely mechanical energy loss in a biological material' (35).

Much of the fluid mechanics of Newtonian liquids is, by convention, though not by logic, excluded from rheology. However, it is not necessarily excluded from the science of biorheology (35).

Great advances occurred in biorheology as an organized science during its brief history of thirty-one years. This process began in 1958 with the conference 'The Flow of Blood in Relation to the Vessel Wall', held at charing cross Hospital Medical School of London University (36). In 1959, with communications in different fields, the conference 'Flow Properties of Blood and other Biological systems', held at the Physiology Laboratory of Oxford University, was jointly convened by the Faraday society and the British Society of Rheology (27). This led in the same year to the foundation of BIORHEOLOGY - An International Journal, first published in 1962 by Pergamon Press (37).

Certainly the International Society of Biorheology and its International congresses, as well as the growing number of international, national and regional societies and groups of biorheology and its fields have greatly contributed to the advancement of the science of biorheology, as did BIORHEOLOGY and CLINICAL HEMORHEOLOGY, the two official journals of the International society.

The science of biorheology is expanding rapidly to encompass the link with more and more life sciences. At present there are already some seventeen fields which belong to the science of biorheology. Last week, during our congress, communications in about fourteen fields of biorheology were 
given. In Plenary Lectures two new fields marked their onset. Patrick Sourander of the University of Goteborg, Sweden presented 'neurobiorheology' (38), while Shu Chien of the University of California, San Diego, USA, dealt with 'molecular biorheology' (39).

\section{In Conclusion}

Earlier in the Opening Address of this symposium, I have referred to the new and widened scope of the science of biorheology, which Alex Silberberg and I emphasized three years ago in an Editorial of the journal BIORHEOLOGY. I should like to reemphasize that the science of biorheology constitutes the link to many, if not most, life sciences.

Biorheology as a multifaceted scientific discipline is thus the link between those aspects of the life sciences, in which the mechanical response to movement and transport is involved. Biorheology deals not only with mechanical properties. It also involves the structural and functional context in which they occur in nature. Biorheology should, therefore, not be confused with biomechanics or with any of its branches, including biofluid mechanics. According to the definition, which Alex silberberg gave me two days ago in Nancy, 'biomechanics, biofluid mechanics, is mechanics, fluid mechanics applied to biorheological systems' (36). The different fields of biorheology deal with deformation including flow of biological materials in context with life processes.

I should like to summarize briefly in stating that the science of biorheology as the link to other life sciences is expanding rather rapidly to be of importance in numerous life sciences, which thus far had not yet this linkage.

The life science of biorheology will ultimately bring us closer to an understanding of the origin of life. In this continuous groping, the students of biorheology will be 
in the forefront of the life sciences, facing with awe - as all human beings do - the mysteries and wonders of life.

\section{Acknowledgement}

The Author thanks George Bugliarello, President of Polytechnic University, New York, USA and Alex Silberberg of the Polymer Department, The Weizmann Institute of Science, Rehovot, Israel, for helpful discussions.

\section{REFERENCES}

1. BUGLIARELLO, G. Biofluidmechanics: Quo vadimus? Ann. Biomed. Engin. 5, 209-247, 1977.

2. BUGLIARELLO, G. Personal communication, New York, NY, 28 MaY 1989.

3. COPLEY, A.L., KRCHMA, L.C. and WHITNEY, M.E. Humoral rheology $I$. Viscosity studies and anomalous flow properties of human blood systems with heparin and other anticoagulants. J. Gen. Physiol., 26, 49-64, 1942.

4. COPLEY, A.L. Foreword. In: G.W. Scott Blair and D.C. Spanner. An Introduction to Biorheology, AmsterdamOxford-New York, Elsevier Scientific Publ. Co., 1974, pp. V-VIII.

5. COPLEY,A.L. Rheological problems in biology. In: Proceedings of the International congress on Rheology, Holland, 1948. J.M. Burgers et al (Eds.) Amsterdam: North-Holland Publishing Co., 1949, Part I-47 to I-61; Part III-8 to III-11.

6. COPLEY, A.L. The rheology of blood. A survey. I. Colloid Sci., 7, 323-333, 1952 .

7. HARTERT, H.H. and COPLEY, A.L. (Eds.). Theoretical and Clinical Hemorheology. Proc. 2. Internat. Conf. Hemorheology, Heidelberg 1969. Berlin-Heidelberg-New York: Springer-Verlag, 1971, $426 \mathrm{pp}$.

8. COPLEY, A.L. The history of clinical hemorheology. Clin. Hemorhecl. 5, 765-812, 1985; $\underline{6}, 165,1986$. The History of Clinical Hemorheology. Bordeaux, 5. European Conference on Clinical Hemorheology, 29 June-1 July, 1987. (Reprinted by the Conference.)

9. COPLEY, A.L. The endo-endothelial fibrin film and fibrinolysis. Proc. VIII. Internat. Congr. Hematology, Tokyo, Japan, September 1960. Tokyo: Pan-Pacific Press, 
1962, vol. 3, pp 1648-1666

10. COPLEY, A.L. The future of the science of biorheology. Biorheology, 19, 47-69, 1982 .

11. COPLEY, A.I. The endoendothelial fibrin(ogenin) lining and its physiological significance. Biorheology 25 , 377-399, 1988 .

12. O'MALLEY, C.D. and SAUNDERS, J.B. de C.M. Leonardo da Vinci on the Human Body. The Anatomical, Physiological and Embryological Drawings of Leonardo da Vinci. With Translations, Emendations and a Biographical Introduction. New York: Henry Schuman, 1952. In: A.L. Copley (8).

13. MCMURRICH, J.P. Leonardo da Vinci. The Anatomist (14521519). Baltimore, Carnegie Institution of Washington and The Williams \& Wilkins Co., 1930.

14. KEELE, K.D. Leonardo da Vinci on Movement of the Heart and Blood. London, Harvey and Blythe Ltd., 1952.

15. LEONARDO DA VINCI Anatomical Drawings from the Royal Library Windsor Castle. New York, The Metropolitan Museum of Art, 1984.

16. KEELE, K.D. Leonardo da Vinci the anatomist. In: Leonardo da Vinci (15), pp. 10-14, 123,131.

17. SINGER, C. Foreword. In: K.D. Keele (14), pp. V-VIII.

18. ALCOPLEY, L.- COPLEY, A.L. The Creative spark in Art and Science. To be published.

19. OKA, S. Cardiovascular Hemorheology. Cambridge: Cambridge University Press, 1981.

20. COPLEY, A.L. Perihemorheology: The bridge between the vessel-blood organ and the organs it penetrates. Biorheology, 26, 377-388, 1989.

21. COPLEY, A.L. Opening Address. On the validity of classical fluid mechanics in biorheology. In: symposium on Biorheology. A.L. Copley (Ed.). Proc. 4. International Congress on Rheology, Brown University, Providence, RI, 26-30 August, 1963. Part 4. New YorkLondon: Interscience Publ.-John Wiley \& Sons, 1965, pp. 3-10.

22. TRAUBE, J. and WANG, S.H. Ztschr. Physik. Chemie 138, 102- , 1928. Cited by A.L. Copley (21).

23. COPLEY, A.L. Adherence and viscosity of blood contacting foreign surfaces and the plasmatic zone in blood circulation. Nature (London), 181, 551-552, 1958. 
24. COPLEY, A.L. and SCOTT BLAIR, G.W. Comparative observations on adherence and consistency of various blood systems in living and artificial capillaries. Rheol. Acta, 1, 170-176, 1958 .

25. COPLEY, A.L. and SCOTT BLAIR, G.W. Comparative observations on adherence and consistency of various blood systems in living and artificial capillaries. II. Additional note to a previous paper. Rheol. Acta, 1, 665668,1961 .

26. COPLEY, A.L. and THORLEY, R.S. Apparatus for measurement of viscosity and wall adherence. In: A.L. Copley and G. Stainsby Eds. (27), pp. 361-368.

27. COPLEY, A.L. and STAINSBY, G. (Eds.) Flow Properties of Blood and other Biological systems, Oxford University, 1959. London-New York: Pergamon Press, 1960, 464 pp.

28. COPLEY, A.L. Apparent viscosity and wall adherence of blood systems. In: A.L. Copley and G. Stainsby, Eds. (27), pp. 97-121.

29. OKA, S. Theoretical approach to the effect of wall surface condition in hemorheology. In: A.L. Copley, Ed. (30), pp. 55-65.

30. COPLEY, A.L. (Ed.) Hemorheology, Proc. 1. Internat. Conf., Univ. of Iceland, 1966. Oxford - New York: Pergamon Press, 1968, 869 pp.

31. HELMHOLTZ, H.v. Berlin. Monatsber. 215, 1868; Phil. Mag. 36, 337- , 1868. Cited by A.L. Copley (21).

32. COPLEY, A.L. and STAPLE, P.H. Haemorheological studies on the plasmatic zone in the microcirculation of the cheek pouch of Chinese and Syrian hamsters.Biorheology, $1,3-14,1962$.

33. KATCHALSKY, A. and OPLATKA, A. Mechanochemistry. In: E.H. Lee and A.L. Copley (Eds.). Proc. 4. Internat. Congress on Rheology, Brown University, Providence, R.I., USA 26-30 August 1963. Part I. New York-London: Interscience Publ.-John Wiley and Sons, 1965, pp.73-97.

34. SILBERBERG, A. Personal communications. Rehovot, Israel and Nancy, France, 1989.

35. SILBERBERG, A. and COPLEY, A.L. On the scope of the science of biorheology and the aims of BIORHEOLOGY. Biorheology 23, 307-309, 1986.

36. SCOTT BLAIR, G.W. The flow of blood in relation to the vessel wall. Nature (London), 182, 90-91, 1958.

37. COPLEY, A.L. A tribute to Robert Maxwell, founder and 
publisher of Pergamon Press. Biorheology, 25, 5-10, 1988; Thrombosis Research 50, 3-8, 1988; clin. Hemorheol. $8,7-12,1988$.

38. SOURANDER, P. Neurobiorheology. Proposal for a new branch of biorheology. Historical background and current ideas. Biorheology, to be published.

39. CHIEN, S. Molecular biorheology. Biorheology, to be published. 